\title{
Inflammatory myofibroblastic tumor causing unexplained anemia in a toddler: a case report
}

\author{
Mohammad Salameh', lyad Sultan², Maha Barbar ${ }^{2}$, Maysa Al Hussaini ${ }^{3}$, Abdullah Jameel ${ }^{4}$, Khalil Ghandour ${ }^{1}$, \\ Ma'in Masarweh ${ }^{1 *}$
}

\begin{abstract}
Introduction: Inflammatory myofibroblastic tumor is a very rare benign tumor in children that mimics malignant tumors in its aggressiveness locally and by the possibility of recurrence after surgical resection, and causing anemia of chronic disease, which is a decrease in hemoglobin 1 to $2 \mathrm{~g} / \mathrm{dL}$ below normal level in a patient with chronic illness.

Case presentation: A 32-month-old boy from Libya presented with microcytic hypochromic anemia. He had been treated in three countries and five centers without response to medical therapy. He was investigated at our center and found to have a mass in the colon causing intermittent intussusception and bleeding. He was treated surgically, and his condition improved dramatically. The pathology report proved a diagnosis of inflammatory myofibroblastic tumor.

Conclusion: We report a case of an unusual tumor of the gastrointestinal tract causing chronic anemia not responding to medical treatment, and discuss the characteristics of inflammatory myofibroblastic tumor. In our case, we stress the involvement of a multidisciplinary team in treating such a patient who presents with common symptoms and signs but in whom there has been no response to any of the measures and treatment protocols.
\end{abstract}

\section{Introduction}

Anemia of chronic disease is an entity that explains a decrease in hemoglobin, usually 1 to $2 \mathrm{~g} / \mathrm{dL}$ below normal level in a patient with a chronic illness. This form of anemia is multifactorial and can be caused by autoimmune diseases, chronic infections or neoplasms. Erythrocytes are usually normocytic but can be microcytic, in which case distinguishing it from iron-deficiency anemia can be challenging. When anemia of chronic disease is suspected, a systematic approach to explore possible causes should be used to avoid unnecessary investigations and to establish the diagnosis.

Inflammatory myofibroblastic tumor (IMT) is a very rare benign tumor that mimics malignant tumors in its aggressiveness locally and by the possibility of recurrence after surgical resection. Grossly, the tumor is a solid, well-circumscribed, nonencapsulated mass that could be found in many anatomic locations, including the colon, lung, bladder, spleen, breast, pancreas, liver,

\footnotetext{
* Correspondence: mmasarweh@khcc.jo

'Department of Surgery, King Hussein Cancer Center, Amman, Jordan

Full list of author information is available at the end of the article
}

spermatic cord, prostate, peripheral nerves, soft tissue and orbit. The whole mark of these tumors is the spindle cell proliferation, which are in fact myofibroblasts, associated with a variable inflammatory component and thence the name [1]. Herein we report a case of IMT that arises from the transverse colon causing colocolic intussusception, and we discuss the importance of a multidisciplinary approach to reach a diagnosis in such cases.

\section{Case presentation}

A 32-month-old boy from Libya presented with a picture of microcytic hypochromic anemia. He was previously healthy until the age of 16 months, when he was found to have pallor, loss of appetite and hypoactivity. The patient was diagnosed with iron-deficiency anemia (hemoglobin, $7 \mathrm{mg} / \mathrm{dL}$ ) and started on iron supplements with no response to treatment. He underwent extensive investigations in six different institutions and three different countries. He received five blood transfusions and was kept on oral ferrous sulphate.
C Biomed Central

(ㄷ) 2011 Salameh et al; licensee BioMed Central Ltd. This is an Open Access article distributed under the terms of the Creative Commons Attribution License (http://creativecommons.org/licenses/by/2.0), which permits unrestricted use, distribution, and reproduction in any medium, provided the original work is properly cited. 
The patient was started on a gluten-free diet on the assumption of celiac disease, but blood test and endoscopic biopsy results of the upper gastrointestinal (GI) tract were normal. He was also treated with metronidazole because of amoebic cysts in the stool. Two weeks before referral, the patient was diagnosed with Coomb's negative autoimmune hemolytic anemia and was started on prednisone $(2 \mathrm{mg} / \mathrm{kg} /$ day $)$ with a dramatic response as his hemoglobin increased from $7.0 \mathrm{~g} / \mathrm{dL}$ to $9.3 \mathrm{~g} / \mathrm{dL}$ and reticulocytes increased from $1 \%$ to $9 \%$. At our institution, the patient's history and medical record were thoroughly reviewed. He had a history of intermittent abdominal pain associated with chronic constipation treated with laxatives. There were episodes of mucus in the stool associated with streaks of blood. On examination, the child was irritable with facial swelling and abdominal distension. He looked pale with no jaundice. He had clubbing of the fingers. He had normal air entry. Heart auscultation revealed a soft systolic murmur. He had no lymphadenopathy and no hepatosplenomegaly. There were no abdominal masses appreciated on the first visit, but on a later visit, a left side and suprapubic mass was felt, and a hydrocele was found upon scrotal examination. During this time, prednisone was tapered and stopped.

Lower GI endoscopy was performed on the assumption of inflammatory bowel disease; the mucosa of the rectum and sigmoid were normal, but there was a mass in the sigmoid covered by a layer of exudate, and the scope could not go beyond this mass (Figure 1). Lower GI contrast study was carried out to delineate the proximal colon, but the picture was suggestive of intussusception.

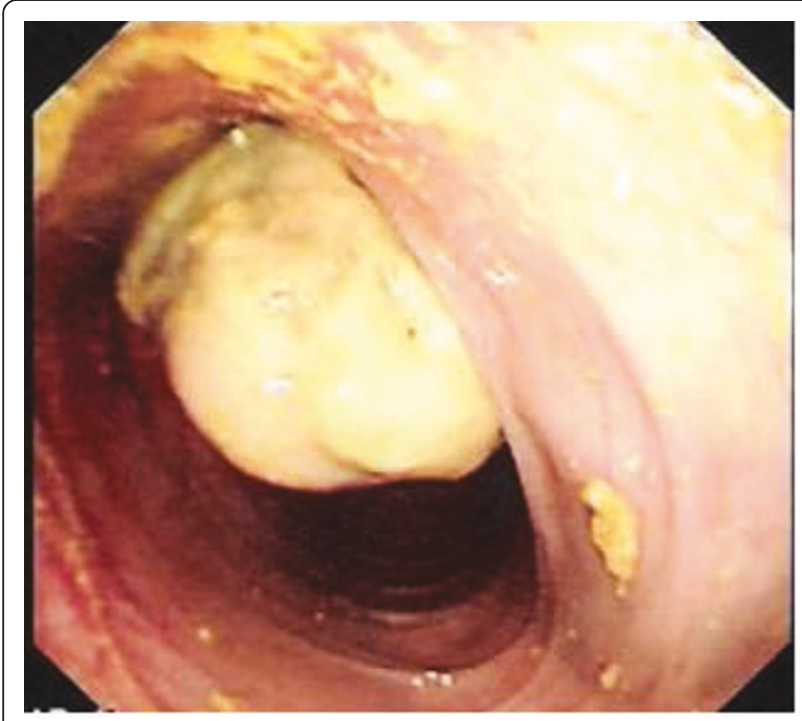

Figure 1 Colonoscopic view.
A computed tomography scan of the abdomen showed a mass in the left side of the abdomen with suspicion of intussusception. Ultrasonography was not helpful in identifying the nature of that mass. Laparotomy was done and showed that there was an intraluminal mass reaching the sigmoid colon originating from the mid transverse colon, causing colocolic intussusception (Figure 2). Resection of the involved segment of the colon was done with end-to-end anastomosis. The patient had a smooth postoperative course, and his hemoglobin level improved dramatically and quickly during the first week after surgery. The histopathology showed extensive surface ulceration and was characterized by a proliferation of plump polygonal or more spindle-shaped cells with amphophilic cytoplasm and vesicular nuclei with prominent nucleoli. The lesion cells were distributed in a patternless fashion within a loose myxoid matrix, which contained numerous thinwalled blood vessels and prominent mixed inflammatory cells, including numerous plasma cells and lymphocytes.

Immunostains showed positivity for S100, keratin AE1/AE3, and more focally for desmin. Smooth muscle actin and anaplastic lymphoma kinase 1 were negative.

\section{Discussion}

IMTs are benign solid tumors that arise in many anatomic sites. The lung is the most common site, but other sites are also reported, including the small and large bowel mesentery, mediastinum, retroperitoneum, omentum, spleen, spermatic cord, prostate, peripheral nerves, soft tissue, orbit and diaphragm [1-3]. IMT is considered a benign tumor with local aggressive course but is not a malignancy in itself.

The presentation of IMT varies depending on the site and includes fever, weakness, abdominal pain, upper GI bleeding, weight loss, vomiting, poor appetite, gastroesophageal reflux, pallor, growth retardation and ascites. These symptoms can appear either alone or in a combination [4]. Laboratory investigations are not specific. The most common finding is microcytic hypochromic anemia refractory to iron therapy (90.9\%), but other

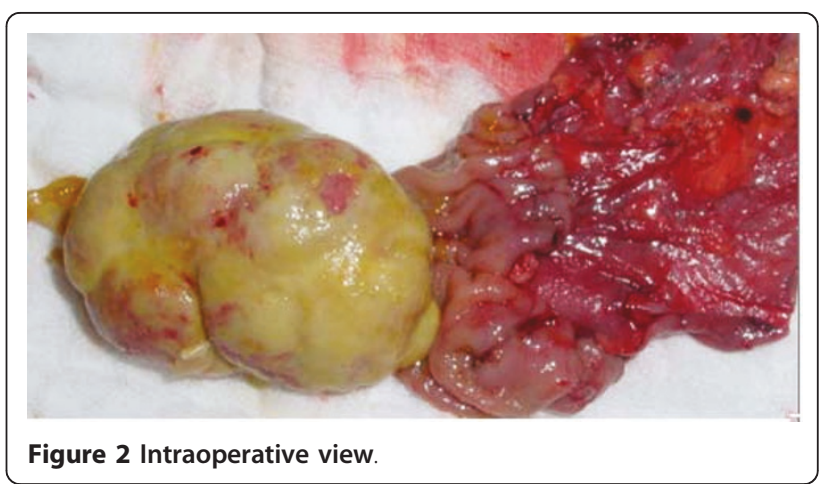


laboratory findings, such as a high erythrocyte sedimentation rate, thrombocytosis, eosinophilia and hypergammaglobulinemia, may be seen $[4,5]$.

Histopathologically, IMT is characterized by spindleshaped cells with chronic inflammatory cell infiltrate consisting of plasma cells, lymphocytes and occasional histiocytes $[1,6]$. These inflammatory cells are usually scattered throughout the lesion to a variable degree [1]. Three different histologic patterns have been described. In the first, myofibroblasts have a spindle appearance and are distributed loosely in a myxoid stroma. The second is more densely packed stromal cells intermingled with an inflammatory component. The third is characterized by hyalinized, hypocellular stroma. These three patterns can be found in a single tumor intermixed closely [1]. All of these features resolve after resection of the tumor [5]. Karnak et al. [5] reported a case with very high leukocyte count and suggest that this could be a good marker for recurrence. Differentiating IMT from sarcoma may be challenging because of the local invasiveness of both pathologies. The lack of mitosis and nuclear atypia in IMT can differentiate it from sarcomas [7].

About $18 \%$ to $40 \%$ of IMTs recur, and most recurrences appear in extrapulmonary lesions that are larger than $8 \mathrm{~cm}$ and are locally invasive $[6,8]$. Retroperitoneal and mesenteric IMT seem to be associated with more frequent recurrences [9]. Complete surgical resection is the treatment of choice and should be advocated unless prohibited [1,9].

Controversy still exists regarding the role of chemotherapy in IMT patients. According to Kovach et al. [1], chemotherapy has been reserved for patients for whom resection is neither complete nor possible. The dosage and regimen of chemotherapy should be adjusted according to the biologic aggressiveness of the tumor, and there is no good evidence to support chemotherapy after complete resection regardless of tumor biology [1]. Radiation treatment showed some benefit in pulmonary IMT [10]. On the other hand, failure of radiation therapy in treating IMT has been reported, confirming surgical excision to be the treatment of choice [11]. Radiation therapy is used in palliative treatment of this tumor, decreasing the mass effect of IMT and in patients whose tumors are not resectable [1]. The use of steroids is also recommended to reduce the inflammatory process that is surrounding the tumor, especially if the tumor is in the central nervous system [1,12]. Using nonsteroidal antiinflammatory drugs as a conservative measure for treatment of patients with IMT whose tumors are not amenable to surgical resection [13].

\section{Conclusion}

In our case, we stress on the involvement of multidisciplinary team in treating such a patient who presents with common symptoms and signs but who has not responded to the measures and treatment protocols; this team should involve medical, surgical, radiology and pathology personnel.

\section{Consent}

Written informed consent was obtained from the patient's father for publication of this case report and accompanying images. A copy of the written consent is available for review by the Editor-in-Chief of this journal.

\section{Acknowledgements}

We would like to thank Christopher D.M. Fletcher, MD, director of Surgical Pathology Department of Pathology Brigham and Women's Hospital Massachusetts, Dana-Farber Cancer Institute for his assistance and opinion in diagnosing this patient.

\section{Author details}

'Department of Surgery, King Hussein Cancer Center, Amman, Jordan.

${ }^{2}$ Department of Pediatrics, King Hussein Cancer Center, Amman, Jordan.

${ }^{3}$ Department of Pathology, King Hussein Cancer Center, Amman, Jordan.

${ }^{4}$ Department of Radiology, King Hussein Cancer Center, Amman, Jordan.

\section{Authors' contributions}

MS was a major contributor in writing the manuscript. IS was the oncologist who took care of the child during his diagnosis and treatment. MB was the gastroenterologist who performed the endoscopy. MAH was the pathologist who reviewed the pathology specimen. AJ was the radiologist involved in the radiologic diagnostic tests. KG was the surgeon who performed the surgical procedure. IS, MB, MAH, AJ and KG also reviewed and contributed to the writing of the manuscript. MM was the surgeon who performed the surgery and was a major contributor in writing the manuscript. All authors read and approved the final manuscript.

\section{Competing interests}

The authors declare that they have no competing interests.

Received: 17 July 2010 Accepted: 17 February 2011

Published: 17 February 2011

\section{References}

1. Kovach SJ, Fischer AC, Katzman PJ, Salloum RM, Ettinghausen SE, Madeb R, Koniaris LG: Inflammatory myofibroblastic tumors. J Surg Oncol 2006, 94(5):385-391.

2. Souid AK, Ziemba MC, Dubansky AS, Mazur M, Oliphant M, Thomas FD, Ratner M, Sadowitz PD: Inflammatory myofibroblastic tumor in children. Cancer 1993, 72(6):2042-2048.

3. Cviko A, Milic Z, Cizmic A, Seiwerth S, Kruslin B: Inflammatory myofibroblastic tumor with extensive involvement of the bowel in a 7year-old child. Croat Med J 1999, 40(4):550-553.

4. Cho MY, Min YK, Kim NR, Cho SJ, Kim HK, Lee KC, Suh SO, Whang CW: Fever of unknown origin as a presentation of gastric inflammatory myofibroblastic tumor in a two-year-old boy. J Korean Med Sci 2002, 17(5):699-703.

5. Karnak I, Senocak ME, Ciftci AO, Cağlar M, Bingöl-Koloğlu M, Tanyel FC, Büyükpamukçu N: Inflammatory myofibroblastic tumor in children: diagnosis and treatment. J Pediatr Surg 2001, 36(6):908-912.

6. Coffin $C M$, Watterson J, Priest JR, Dehner LP: Extrapulmonary inflammatory myofibroblastic tumor (inflammatory pseudotumor): a clinical and immunohistochemical study of 84 cases. Am J Surg Pathol 1995, 19(8):859-872.

7. Sanders BM, West KW, Gingalewski C, Engum S, Davis M, Grosfeld JL: Inflammatory pseudotumor of the alimentary tract: clinical and surgical experience. J Pediatr Surg 2001, 36(1):169-173.

8. Dao AH, Hodges KB: Inflammatory pseudotumor of the pelvis: case report with review of recent developments. Am Surg 1998, 64(12):1188-1191. 
9. Huang CC, Lien HH, Chen DF, Tsai MS: Pediatric intra-abdominal inflammatory myofibroblastic tumor. Asian I Surg 2006, 29(1):58-61.

10. Hoover SV, Granston AS, Koch DF, Hudson TR: Plasma cell granuloma of the lung, response to radiation therapy: report of a single case. Cancer 1977, 39(1):123-125.

11. Mehta J, Desphande S, Stauffer JL, Stanford R, Fernandez E: Plasma cell granuloma of the lung: endobronchial presentation and absence of response to radiation therapy. South Med J 1980, 73(9):1198-1201.

12. Chun YS, Wang L, Nascimento AG, Moir CR, Rodeberg DA: Pediatric Inflammatory myofibroblastic tumor: anaplastic lymphoma kinase (ALK) expression and prognosis. Pediatr Blood Cancer 2005, 45(6):796-801.

13. Su W, Ko A, O'Connell T, Applebaum H: Treatment of pseudotumors with nonsteroidal anti-inflammatory drugs. J Pediatr Surg 2000, 35(11):1635-1637.

doi:10.1186/1752-1947-5-69

Cite this article as: Salameh et al:: Inflammatory myofibroblastic tumor causing unexplained anemia in a toddler: a case report. Journal of Medical Case Reports 2011 5:69.

\section{Submit your next manuscript to BioMed Central} and take full advantage of:

- Convenient online submission

- Thorough peer review

- No space constraints or color figure charges

- Immediate publication on acceptance

- Inclusion in PubMed, CAS, Scopus and Google Scholar

- Research which is freely available for redistribution

Submit your manuscript at www.biomedcentral.com/submit 